\title{
A Crew Resource Management Training for Improving Team Performance of Operators in the APR-1400 Nuclear Power Plant
}

\author{
Sa Kil Kim ${ }^{1}$, Seong Nam Byun ${ }^{1}$ \\ ${ }^{1}$ Department of Industrial Engineering, Kyung Hee University, Seoul, Korea \\ byun@khu.ac.kr
}

\begin{abstract}
The Nuclear power plant (NPP) industries in Korea have been making efforts to reduce the human errors which largely contributed to 120 nuclear reactor trips from the year of 2001 to 2006 . This study aims to develop a Crew Resource Management (CRM) training program that helps to improve plant performance by reducing the number of the reactor trips caused by the operators' errors.

The CRM program was developed with focusing on non-technical skills, such as leadership, situation awareness, teamwork, and communication, which have been widely known to be critical for improving the operational performance. In this study, the CRM program was applied to the operators performing simulation scenarios in the mockup of the main control room of the APR-1400. The CRM program was proceeded with the lectures, emergency operation procedure scenarios designed by the process expert, task monitoring, and debriefings. Finally we verified the effectiveness of CRM training through the attitudes test and BARS(Behaviorally Anchored Rating Scale) to measure learning that has resulted from participation in the training program. The implication of the evaluation results was discussed in detail.
\end{abstract}

Keywords: Crew Resource Management, team performance, leadership, situation awareness, teamwork, communication

\section{Introduction}

In recent years, the nuclear power industry has recognized the importance of integrating non-technical and team skills training with the technical training given to its control room operators [8]. Both the Three Mile Island and Chernobyl accident were examples of human and mechanical failure [6]. Consequently $\mathrm{CRM}$ (Crew Resource Management) training courses have been designed, such as the human performance foundation course which is used to provide human factors training to control room staff in British Energy, a nuclear power company[4]. CRM was developed as a response to new insights into the causes of aircraft accidents which followed from the introduction of flight recorders and cockpit voice recorders into modern jet aircraft [1]. CRM first became widely used in the commercial airline industry, but military aviation, shipboard crews, medical and surgical teams, offshore oil crews, and other high-consequence, high-risk, time-critical industry teams soon followed [5].

This type of training is not only being carried out in the UK, similar CRM courses using simulators have been used in nuclear power utilities in the USA and France. The Institute of Nuclear Power Operations (INPO) has developed a generic 28 hours training course for improving teamwork in the control room. The course is designed to improve performance in communication, inquiry, advocacy, leadership, conflict management, and critique performance [18].

Roth and O'Hara (1998) reviewed the introduction of a computer-based display system into a NPP control room. One component in particular, a computer-based procedure system, changed the ways in which control room personnel when using procedures. Many of the operators' comments focused on the need for more practice on crew-interaction skills, including focused training on their new roles and responsibilities, communication, and coordination [11].

Sebok(2000) emphasized that human-system interaction research generally focuses on the individual user and supporting individual operator performance through appropriate interface design. He performed the OECD Halden Reactor Project compared the effects of interface design and staffing levels on various aspects of team performance. Teams of nuclear power plant operators participated in challenging simulator scenarios, working in either a simulated conventional plant, with a hard control interface, or in a simulated advanced plant, with a computerized interface. He found that combinations of interface design and staffing levels supported different aspects of performance. Larger crews consistently performed better than smaller crews in the conventional plant. In the advanced plant, both crew types performed equally well; however, smaller crews had better situation awareness than larger crew. On that project, he specially emphasized the importance of team performance in advanced plant.

Korea Hydro \& Nuclear Power Company has been continuously developing a new reactor model, APR-1400(Advanced Power Reactor-1400), to improve public acceptance and enhance economics as a Korean advanced nuclear power plant. The design of instrumental and control systems for APR-1400 is applied of fully digital systems. For example, soft-control, computerized procedure systems, large display panels (LDP), and an advanced alarm system were applied to APR-1400.

APR-1400 has been validating through performance-based tests to determine whether it acceptably supports safe operation of the plant [7]. On 
the process of the verification and validation, we found that team performance was different among the crews. To solve this problem we suggested that team training such as Crew Resource Management (CRM) training is necessary to the operators of advanced main control room. Our team developed a CRM training program that helps to improve plant performance by reducing the number of the reactor trips caused by the operators' errors.

Finally we verified the effectiveness of CRM training through the attitudes test to measure learning that has resulted from participation in the training program. This involves measuring participant's skills, knowledge or attitudes before training, and again some tines after completing training to measure the amount of learning that has occurred.

\section{Development of CRM Training Program}

CRM training program is based on the work we conducted to develop non-technical and human factors training to apply it to the Nuclear Power Plant (NPP). And also the program is based on a number of guidelines from the literature $[2,12,13,14,15$, etc.]. The program is similar to the event-based approach to training that many researchers have applied in other domains: airlines, aircrafts, medical operations, railroads, offshore oils, etc.

Figure 1 shows an overview of the structure and procedure that we employed for developing effective CRM training.

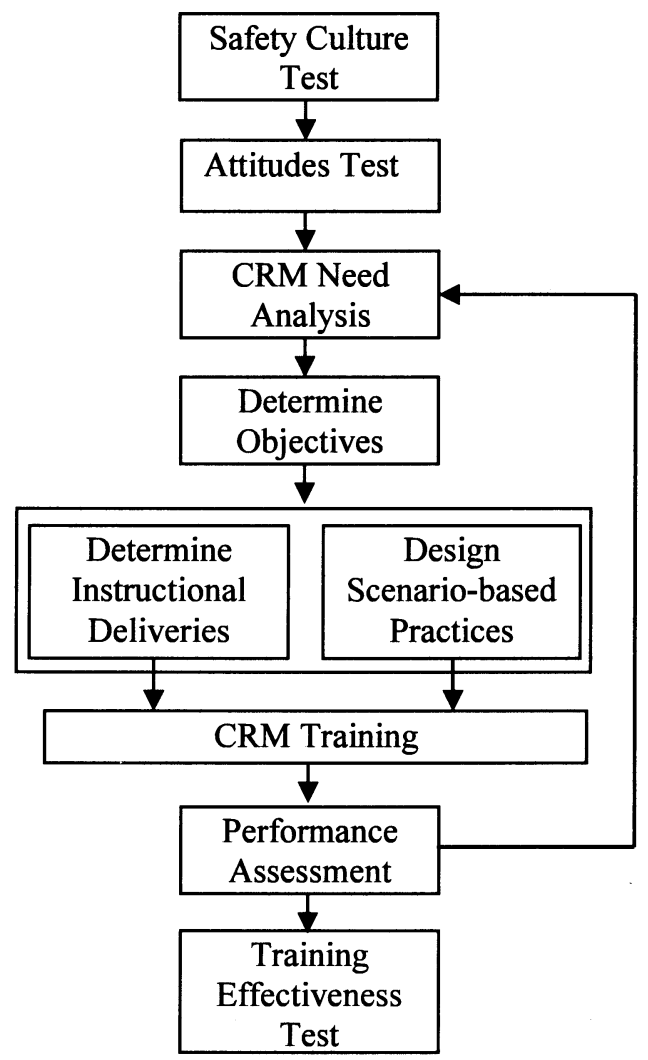

Figure 1. CRM training structure and procedure

\section{a) Safety Culture Test}

Organizations where the culture is not already aligned to the CRM philosophy should not be deterred from introducing it. In other words, organizations lacking such as culture are likely to take longer to see initial improvement and to realize the full benefits of CRM[3]. To make plans for CRM training, we should determine how long and how many times the training will be conducted using the results of the safety culture test.

In this study, we used the questionnaire has been adapted from an earlier survey developed by professor James Reason for the purpose of evaluating the nature and strength of an organization's safety culture[3]. The questionnaire consists of 20 items and each item provides three optional scales by 1-0.5-0. Higher scores on this questionnaire indicate that an organization has more of attributes associated with a good safety culture.

\section{b) Attitudes Test}

Generally attitudes test is used to determine whether employee is suitable to his/her task or not. Attitudes to leadership, stress, teamwork, work values, error, organizational climate, and others however are important to enhance CRM training. Helmreich et al.(1993) developed the Flight Management Attitudes Questionnaire(FMAQ) to implement CRM training for aviations. They extended their work with aviation industry to examine the attitudes of hospital operating theater personnel to teamwork and safety[9].

To examine the attitudes of operators, we used Operators Management Attitudes Questionnaire (OMAQ) which has been adapted from the FMAQ in this study. The OMAQ consists of 57 items and has Likert's 5 point scale system. The results from the questionnaire can be used in a number of ways associated with CRM training:

- To help design CRM course content by suggesting organizational issues of greatest relevance;

- To identify commonly-held attitudes amongst operators that may be incorrect and therefore threaten safety;

- To provide baseline data on operator attitudes and organizational issues that can be compared with data obtained after a CRM training program has been implemented.

\section{c) CRM Need Analysis}

CRM need analysis process is to define training needs. The process will help organizations intending to use the basic CRM training materials to[3]:

- Develop a profile training priorities for an individual operator role, designed to reduce risk associated with human performance;

- Identify training gaps, i.e., where relevant training is not currently provided;

- Customize a CRM training syllabus;

- Evaluate possibilities for joint training. 
It is recommended that this analysis be undertaken by one or more subject matter experts (SMEs) who have current knowledge of the job requirements and context of the role in question and understand the human factors associated with safety events in their own organization. SMEs should evaluate the training needs as the importance of each activity. The importance of an activity can be defined as a combination of the impact of the activity on a safety outcome and the frequency with which the task is undertaken. In this study, each activity as a behavior marker was classified 9 categories: leadership, task management, teamwork, communication, risk management, situational awareness, decision making, emergency management, and self-management.

\section{d) Determine Objectives}

Above-mentioned safety culture test, attitudes test, and need analysis are the processes of preparing CRM training. To make plans for CRM training, firstly we should determine objectives, which are as follows[1]:

- To enhance crew and management awareness of human factors which could cause or exacerbate incidents which affect the safe conduct of operations.

- To enhance knowledge of human factors and develop CRM skills and attitudes which when applied appropriately could extricate an operation from incipient accidents and incidents whether perpetrated by technical or human factor failings.

- To use CRM knowledge, skills and attitudes to conduct and manage operations, and fully integrate these techniques throughout every facet of the organization culture, so as to prevent the onset of incidents and potential accidents.

- To use these skills to integrate commercially efficient operations with safety.

- To improve the working environment for crews and all those associated with operations.

- To enhance the prevention and management of crew error.

\section{e) Determine Instructional Deliveries}

Training provider should include a detailed CRM course syllabus, based on the standard operating procedure, in their training manual with appropriate training media. The instructional deliveries should be included that: CRM introduction, human information processing, communication, leadership and followership, decision making and problem solving, and situational awareness, etc.

Additionally there are basic principles for developing training course content[15]. Best practice principles for CRM training specify that the training materials and learning activities have demonstrable relevance to the day-to-day operational activities of the participants. A second best practice principles requires that the scenarios and case studies used for training purposes should be also realistic and relevant. Lastly, it is also important that all materials be formally assessed as suitable for the reading and comprehension characteristics of the user population.

\section{f) Design Scenario-Based Practices}

To maintain the integrity of the training process, training methods should be focused on objectives. The objectives would be to ensure that participants develop the right knowledge, skills and attitudes[1]. In behavioral training, where behavioral skills development and attitude changes are being encouraged, the interactive process of the actual training is what is of paramount importance. In other words, knowledge, ability and motivation are all necessary to effect enduring changes in behavior as a competence.

\section{g) Conducting CRM Training}

Training should be conducted by volunteer peer facilitators, that is, co-workers of the course participants who are periodically removed from operational duties to deliver the CRM program. Peer facilitators are preferred over qualified internal or external trainers because they speak the language of the participants, are deemed to have a more thorough knowledge of current workplace issues, and understand the prevailing organizational and professional cultures.

CRM training is conducted by instructional lectures and scenario-based practices. Topics are ideally delivered in a single training event a number of consecutive days, rather than dispersed in small segments over many months. And the term recurrent training refers to a regular, often annual learning activity designed to consolidate the training experience, competence of employees, and safety cultures.

\section{h) Performance Assessment}

Purpose of team performance assessment is to correct the operators' wrong activities through evaluating CRM skills such as leadership, team workload, shared situational awareness, communication, coordination, etc.

Team-based activity involves multiple actors with multiple goals performing both teamwork and individual task activity. The activity is typically complex and may be dispersed across a number of different geographical locations. Consequently there are a number of different team performance assessment methods available to human factors practitioner, each designed to assess certain aspects of team performance in complex systems[17].

Team performance assessment methods can be broadly classified into the following categories:

- Team task analysis(TTA) methods

- Team cognitive task analysis methods

- Team communication assessment methods

- Team behavioral assessment methods

- Team mental workload assessment methods

\section{i) Training Effectiveness Test}

Accurate evaluation contributes to understanding the impact of the training, in addition to identifying ways in which the training can be continuously improved to 
focus on area of most benefit to participants. Multiple level of the available evaluation process should be used to demonstrate the extent to which CRM training is effective. There are four levels of evaluation that can be used to measure the effectiveness of CRM training[10]. Kirkpatrick's four-level model for training evaluation involves gathering data on:

- Level 1 (Reaction) - Participant responses to the training

- Level 2 (Learning) - The extent of learning that takes place

- Level 3 (Transfer) - The application of learning to operational tasks

- Level 4 (Results) - Tangible organizational benefits

Level 1 evaluation measures participant reactions to a training course by means of post-training questionnaire. Level 2 training evaluation attempts to measure learning that has resulted from participation in the training program. Level 2 evaluation of CRM training requires a context-specific attitude questionnaire, to be administered pre- and post- CRM training. Level 3 evaluation focuses on the transfer of learning achieved as a result of completing a training course. Level 3 evaluation attempts to answer the question to what extent are the desired skills, knowledge, or attitudes being applied in the operational environment by participants. Lastly level 4 evaluation focuses on the identification of tangible organization benefits that can be to a training program. Level 4 evaluation seeks to identify organizational benefits such as enhanced safety, increased productivity or quality, decreased operating costs, and higher return on investment (ROI).

\section{CRM Training in the APR-1400}

To investigate the effects of CRM training, an experiment was conducted using a between-subjects design with two crews of operators participating in six simulated scenarios during CRM training. A crew consisted of five licensed NPP operators: shift supervisor, control room assistant, reactor operator, turbine operator, and electric operator. One crew participated in the CRM training program, the other crew did not.

\section{a) Designing Training Program}

We conducted safety culture test and attitudes test to design training program for the crew. The score of safety culture test was 18 points. The score means that the organization has more of the attributes associated with a good safety culture so that CRM training will fit well with existing culture.

We used result of attitudes test to identify commonly-held attitudes amongst operators that may be incorrect and therefore threaten safety. We reflected items which were below the average point on designing training program.

Lastly we reflected the results of CRM need analysis on designing training program. The results of CRM need analysis is shown table 1 .

Table 1. Results of CRM need analysis

\begin{tabular}{|l|c|c|}
\hline \multicolumn{1}{|c|}{ Task Category } & $\begin{array}{c}\text { Priority } \\
\text { Score }\end{array}$ & $\begin{array}{c}\text { Priority } \\
\text { Ranking }\end{array}$ \\
\hline Leadership & 29.5 & 7 \\
\hline Task management & 29.5 & 7 \\
\hline Teamwork & 24.8 & 9 \\
\hline Communication & 33.8 & 2 \\
\hline Risk management & 31.3 & 5 \\
\hline Situational awareness & 33.5 & 3 \\
\hline Decision making & 32.5 & 4 \\
\hline Emergent management & 35.0 & 1 \\
\hline Self management & 30.0 & 6 \\
\hline
\end{tabular}

\section{b) Preparing Experiment}

Two crews from Yeong-Gwang and Ul-Jin NPP participated in this study. Each crew has a similar experience in operating main control room. Two process experts participated in the experiment as performance raters. These personnel had between 20 and 30 years of nuclear process experience.

Experimental scenarios consist of six multiple-fault scenarios. All six scenarios required operators to perform mitigation actions to control the plant and required some degree of coordination with personnel outside the control room, as simulated by the training specialist. The six scenarios are identified below:

- ESDE at the operation console

- LOCA at the operation console

- SGTR at the operation console

- ATWT at the safety console

- LOCA at the safety console

- Remote shutdown console scenario

Several types of equipment collected data in this study: videotapes with audio recordings, paper questionnaires, and simulator records. Videotapes were used for monitoring crew's performance throughout the entire scenario, with three cameras recording the crew's actions from different perspectives. Questionnaires were used for colleting team coordination scores. Eight simulator records, a variable $\log$ and event $\log$, were made for each scenario. These logs contained time stamps for comparison with the videotape.

Simulator for advanced main control room (MCR) of APR-1400 was used for this experiment. The simulator is shown in figure 2 .

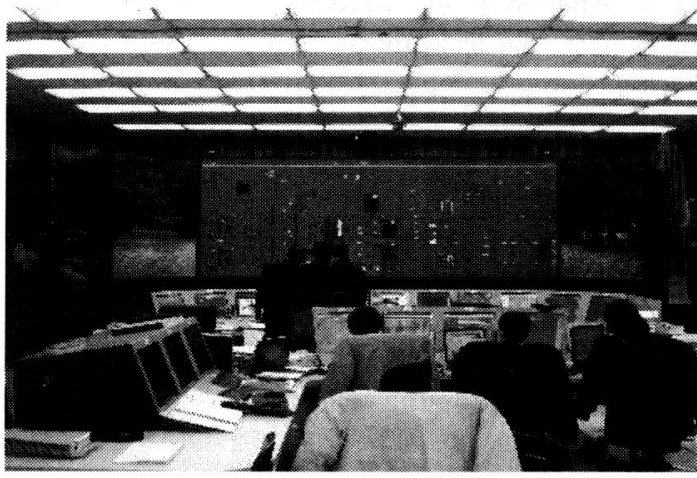


Figure 2. Simulator for APR-1400 MCR

\section{c) Training and Performance Assessment}

All experimental participants received appropriate training for the simulator condition, differences between conventional MCR and advanced MCR, and technical knowledge/skills to operating the simulator in which they participated during two week.

To validate CRM training effectiveness, just one crew received CRM instructional lectures and scenario-based practices additionally. Training course for two crews is shown in table 2 .

Table 2. Training course

\begin{tabular}{|c|c|c|c|}
\hline Training & Contents & $\begin{array}{c}\text { Crew } \\
\text { A }\end{array}$ & $\begin{array}{c}\text { Crew } \\
\text { B }\end{array}$ \\
\hline \multirow[t]{11}{*}{ Lectures } & Operating philosophy & $\mathrm{O}$ & 0 \\
\hline & $\begin{array}{l}\text { LDP/Soft } \\
\text { Control/Alarm/CPS }\end{array}$ & 0 & $\mathrm{O}$ \\
\hline & Difference of process & $\mathrm{O}$ & $\mathrm{O}$ \\
\hline & Condition of the Simulator & $\mathrm{O}$ & 0 \\
\hline & Introduction of CRM & $\mathrm{O}$ & \\
\hline & $\begin{array}{l}\text { Human information } \\
\text { processing }\end{array}$ & 0 & \\
\hline & Communication skills & 0 & \\
\hline & Leadership/Followership & 0 & \\
\hline & $\begin{array}{l}\text { Decision making and } \\
\text { problem solving }\end{array}$ & 0 & \\
\hline & Situational awareness & $\mathrm{O}$ & \\
\hline & CRM principles & $\mathrm{O}$ & \\
\hline \multirow[t]{3}{*}{ Practices } & Scenario-based practices & 0 & 0 \\
\hline & $\begin{array}{l}\text { Team skills } \\
\text { evaluation/debriefing }\end{array}$ & 0 & \\
\hline & $\begin{array}{l}\text { Team tasks } \\
\text { monitoring/debriefing }\end{array}$ & 0 & \\
\hline Evaluations & TDSV/debriefing & 0 & 0 \\
\hline
\end{tabular}

To provide training competence and feedback, we conducted performance assessment through the TDSV and debriefing after finishing all training course. TDSV was conducted by two processing experts during the practice training period. The experts observed crew performance throughout the scenarios and rated various aspects of team performance using four measuring tools: NASA-TLX(National Aeronautics and Space Administration - Task Load Index), KSAX(Korea Situation Awareness index), CDA(Coordination Demands Analysis), and BARS(Behaviorally Anchored Rating Scale). We used the NASA-TLX and KSAX for measuring individual performance and used the CDA and BARS for measuring team performance.

\section{c) CRM training Effectiveness}

We conducted effectiveness test through Kirkpatrick's four-level model. In this study, however we just conducted level 2 and 3 evaluations to compare crew A with Crew B. We conducted attitudes test after finishing all CRM training for the level 2 evaluation and analyzed individual and team performance for the level
3 evaluation. The results of the level 2 evaluation are shown in table 3.

Table 3. Results of attitudes test

\begin{tabular}{|l|c|c|c|}
\hline & Mean & $\begin{array}{c}\text { Standard } \\
\text { Deviation }\end{array}$ & P-value \\
\hline $\begin{array}{l}\text { Crew A } \\
- \text { Crew B }\end{array}$ & 0.081 & 0.410 & 0.143 \\
\hline $\begin{array}{l}\text { Pre Crew A } \\
- \text { Post Crew B }\end{array}$ & -0.295 & 0.394 & 0.000 \\
\hline $\begin{array}{l}\text { Mean value of Crew A(pre): } 3.34 \\
\text { Mean value of Crew B: } 3.26 \\
\text { Mean value of Crew A(post): } 3.64\end{array}$ \\
\hline
\end{tabular}

Table 3 presents the t-test results of operators' attitudes. There was no difference between the uncontrolled group(Crew A) and controlled group(Crew B). And there was a significant difference between attitudes of pre-training and attitudes of post-training in case of Crew A. The result shows the CRM training effectiveness significantly.

The results of level 3 evaluation are shown in table 4 . There was no difference of team coordination between Crew A and Crew B. Differences in mental workload for two crews were revealed $(p=0.000)$. More less mental workload values of Crew A than Crew B may show the training effects. Lastly differences in situational awareness for two crews were revealed $(p=0.000)$. More much situational awareness values of Crew $\mathrm{A}$ than Crew $B$ may reveal the training effects too.

Table 4. Results of performance assessment

\begin{tabular}{|c|c|c|c|}
\hline & Mean & $\begin{array}{c}\text { Standard } \\
\text { Deviation }\end{array}$ & P-value \\
\hline $\begin{array}{l}\text { BARS } \\
\text { (Team } \\
\text { Coordination) }\end{array}$ & 0.083 & 0.168 & 0.866 \\
\hline $\begin{array}{l}\text { NASA-TLX } \\
\text { (Mental } \\
\text { Workload) }\end{array}$ & -3.833 & 4.955 & 0.000 \\
\hline $\begin{array}{l}\text { KSAX } \\
\text { (Situation } \\
\text { Awareness) }\end{array}$ & 4.867 & 4.377 & 0.000 \\
\hline \multicolumn{4}{|c|}{$\begin{array}{l}\text { BARS mean value of Crew A: } 6.56 \\
\text { BARS mean value of Crew B: } 6.55 \\
\text { NASA-TLX mean value of Crew A: } 21.00 \\
\text { NASA-TLX mean value of Crew B: } 24.83 \\
\text { KSAX mean value of Crew A: } 27.90 \\
\text { KSAX mean value of Crew B: } 23.03\end{array}$} \\
\hline
\end{tabular}

\section{Concluding Remarks}

This study was a realistic experiment comparing the effects of CRM training on attitudes and crew performance. The findings reveal effectiveness of CRM training program we developed.

Experimental study verified that CRM training affects the improvement of individual performance and positive changes of attitudes except team coordination. Team coordination measured by BARS had a problem that the consistency between two raters was not significant. And it was revealed that only Crew B had an experience with operating advanced MCR for the human 
factors engineering validation \& verification a few months ago.

Consequently the CRM training program will be a way to improve individual and team performance and to reduce human errors in operating advanced MCR.

\section{References}

[1] CAA(2006), Crew resource management training: Guidance for flight crew, CRM instructors and CRM instructor-examiners, Safety Regulation Group, Civil Aviation Authority, West Sussex.

[2] Cannon-Bowers, J., Salas, E., \& Grossman, J.(1991), Improving tactical decision making under stress: Research directions an applied implications, Paper presented at the International Applied Military Psychology Symposium, Stockholm, Sweden.

[3] Dédale Asia Pacific(2007), Final Report, National Rail Resource Management Project: Guidelines for rail resource management, Melbourne/Sydney:

PTSV/ITSRR.

[4] Flin, R., O'Connor, P., and Mearns, K.(2002), Crew resource management: improving team work in high reliability industries, Team Performance Management, Vol.8, ABI/INFORM Global, pp.68.

[5] FRA(2007), Rail crew resource management: Pilot rail CRM training development and implementation, DOT/FRA/ORD-07/02.I, Federal Railroad Administration, Washington, DC.

[6] Gaddy, C. and Wachtel, J.(1992), Team skills training in nuclear power plant operations, in Swezey, $R$. and Salas, E.(Eds.), Teams: Their training and performance, Ablex, Norwood, NJ.

[7] Ha, J.S., Seong, P.H, Lee, M.S., and Hong, J.H.(2007), Development of human performance measure for human factors validation in the advanced MCR of APR-1400, IEEE Transaction on Nuclear Science, Vol.54, No.6, pp.2687-2700.

[8] Harrington, D. and Kello, J.(1993), Systematic evaluation of nuclear operator team skills training, paper presented at the American Nuclear Society, San Francisco, CA, November.

[9] Helmreich, R.L., Merritt, A.C., Herman, P. Gregorich, S., Wiener, E.(1993), The Flight Management Attitudes Questionnaire, NASA/University of Texas FAA Technical Report 93-5, Austin: University of Texas.

[10] Kirkpatrick, D.L.(1994), Evaluating training programs: The four levels, San Francisco, CA: Berrett-Koehler.

[11] Roth, E. and O'Hara, J.(1998), Integrating digital and conventional HSIs: Lessons learned from a control room modernization program, BNL letter Report J6012-T3-4-5/98, Upton, NY: Brookhaven National Laboratory.

[12] Salas, E., Burke, C.S., \& Cannon-Bowers, J.A.(2000), Teamwork: emerging principles, International Journal of Management Review, Vol.2, No.4, pp.339-356.
[13] Salas, E. \& Prince, C.(1999), A Methodology for Enhancing Crew Resource Management Training, Human Factors, Vol.41, No.1, p.161-172.

[14] Salas, E. \& Kendall, D.L.(2004), Measuring team performance: a review of current methods and consideration of future research, v.5, pp.307-326.

[15] Salas, E., Wilson, K.A., Burke, C.S., Wightman, D.C., \& Howse, W.R.(2006), A checklist for Crew Resource Management training, Ergonomics in Design, Vol.14, No.4, pp.6-15.

[16] Sebok, A.(2000), Team performance in process control: influence of interface design and staffing levels, Ergonomics, Vol.43, No.8, pp.1210-1236.

[17] Stanton, N.A., Salmon, P.M., Walker, G.H., Baber, C., Jenkins, D.P.(2005), Human factors methods: a practical guide for engineering and design, Ashgate Publishing Limited.

[18] USNRC, Human-system interface and plant modernization process: Technical basis and human factors review guidance(NUREG/CR-6637; BNL-NUREG-52567), Washington DC: US Nuclear Regulatory Commission. 